\title{
Sexual Health in Adult Men with Spina Bifida
}

\author{
Gary W. Bong and Eric S. Rovner* \\ Department of Urology, Medical University of South Carolina, Charleston, SC, USA \\ E-mail: rovnere@musc.edu
}

Received March 24, 2007; Accepted July 5, 2007; Published September 1, 2007

\begin{abstract}
Medical and surgical advances in the treatment of spina bifida (SB) have resulted in increasing numbers of patients reaching adulthood. As such, issues related to sexual maturity are being investigated to offer optimal healthcare to men with spina bifida. This report constitutes a review of the current literature relating to adults with spina bifida and issues of sexuality, erectile dysfunction and fertility. In general, adult males with spina bifida have normal sexual desires and an interest in addressing these issues with healthcare providers. Sexual education and access to intimacy are delayed compared to the general population. $75 \%$ of men achieve erections, but maintaining erections is a problem and some may be merely reflexive in nature. The many of these men show marked improvement with sildenafil. In SB erectile dysfunction and infertility are related to the level of neurological lesion with the best performance status in those with sacral lesions and intact reflexes. Men with lesions higher than T10 are at risk for azoospermia. There is an increased risk of neural tube defects in the children of men with spina bifida, but the current incidence with modern folic acid therapy is unknown. As the number of males with spina bifida reaching sexual maturity increases, further investigation into sexuality, sex education, intimacy, and treatments for erectile dysfunction and infertility will be needed.
\end{abstract}

KEY WORDS: spina bifida, myelomeningocele, sexuality, erectile dysfunction, fertility

\section{INTRODUCTION}

Spina bifida (SB), a group of developmental abnormalities resulting from neural tube closure defects, affects less than 1/1000 births[1]. Medical advances over the last 4 decades, primarily surgical closure of open defects, shunting procedures and attention towards renal preservation, have markedly increased the life expectancy of these individuals. As such, there are growing numbers of men with SB reaching sexual maturity. Information regarding the sexual health of these individuals, however, is limited. Psychosexual development and sexual function are clearly affected by SB and further investigation is required to better manage males reaching puberty, starting relationships and desiring children. We review the current understanding on sexuality, erectile function and fertility in adult men with SB. 


\section{SEXUALITY}

Patients with severe congenital handicaps, including SB, often fail to develop normal sexuality due to impaired self esteem, dependence on care givers and lack of privacy[2]. Even patients with minor or inconspicuous abnormalities may have impaired or delayed sexuality secondary to issues that keep individuals from developing normal peer groups, such as urinary or fecal incontinence.

Those who are overtly handicapped, especially those who are wheelchair dependent, are often presumed to be asexual[3]. This assumption is a gross error on the part of caregivers and health care providers. Indeed, men with SB do have decreased access to sexual encounters compared to normal healthy peers, but sexual desire usually remains intact if cognitive function is normal. $80-100 \%$ of postpubertal men with SB report normal sexual desires and fantasies and are actively interested in sexual activity[4,5,6]. A recent study utilizing a validated erectile function questionnaire demonstrated that $40 \%$ of men with SB engage in sexual activity[7]. These tended to be the older men (mean age 32) and those who no longer lived with their parents. Compared to the general population, initiation of sexual activity in SB males is delayed.

Sexual education is also delayed in these patients. In adult men without cognitive impairment, 23$28 \%$ are not aware of basic concepts related to intercourse and reproduction[5,8]. In the past 3 decades, the burden of sexual education has shifted from peers and parents to the classroom. This is ultimately beneficial to patients with SB who tend to have minimal peer groups, but are increasingly incorporated into the public school system. In a questionnaire-based study of 57 adult men with SB, 58\% learned sexual education in school, $18 \%$ from parents, $14 \%$ from peers, $18 \%$ from books and $6 \%$ from TV, movies or other sources[8]. Although most young adults with SB are satisfied with the amount of general sex education they had received, $95 \%$ of patients and $59 \%$ of their parents stated they had inadequate knowledge of sexual health as it relates to spina bifida[9]. Only one-third had discussed sexuality issues with a doctor, but $93 \%$ and $100 \%$ of patients and parents, respectively, would discuss these issues if initiated by the health care provider.

\section{ERECTILE FUNCTION}

The prevalence of erectile dysfunction (ED) in adult men with SB is approximately $75 \%$ based on modern criteria and is dependent upon the level of neurologic lesion[7,10]. All SB males with intact sacral reflexes and urinary continence are potentially potent. With absent sacral reflexes, the presence and severity of ED is variable. Diamond et al. reported that $64 \%$ of men with a lesion at T10 or lower obtained erections compared to only $14 \%$ with a lesion above T10[10]. A similar relation with neurologic level was demonstrated by Sandler who measured nocturnal penile tumescence and noted that the number of erections was related to sensory level[11]. There is some doubt with higher lesions as to whether erections are truly sexual in nature versus reflexive. Erections in individuals with lower lesions, however, appear to be initiated under normal stimuli. Hirayama demonstrated that in 22 males (mean age 24), 95\% achieved erection by visual stimulation alone and $86 \%$ by tactile stimulation[6]. While the incidence of erection obtained with stimulation were high, only $27 \%$ of the patients capable of obtaining erections were satisfied with penile rigidity. Difficulty in maintaining an erection is also a major component to ED in these men[7].

As with erections, men with SB have variable ejaculation and orgasms. Up to $75 \%$ of SB men experience ejaculation[6,8,12]. This tends to be dripping in nature and may not necessarily be associated with a sexual sensation typical of orgasm. Decter et al. reported that $20 \%$ of men studied did not positively perceive ejaculation and this may be due, in part, to absent penile sensation[8]. 


\section{TREATMENT OF ERECTILE DYSFUNCTION}

Erectile dysfunction contributes to a lack of confidence, poor body image and difficulty maintaining intimate relationships[13]. Treatment of ED in the spina bifida population is therefore important to several aspects of sexuality. These patients do not typically have anatomic abnormalities with penile architecture, as in the exstrophy-epispadias complex, and as such, often respond to conventional impotence management. Sildenafil, a Type 5 phosphodiesterase (PDE5) inhibitor, was shown to be effective in men with SB and $\mathrm{ED}[13,14]$. 80\% of patients responded in a dose dependent manner with the best efficacy at the $50 \mathrm{mg}$ dose. Duration of erections, a primary component to ED in this population, increased 266\%. One patient experienced success with the $100 \mathrm{mg}$ dose after failing to see improvement in erections at the lower doses.

Neurological bypass has also been reported to result in an awareness of sensation in the penis. In one study, 3 patients received an ilioinguinal nerve transposition to the dorsal nerve of the penis with successful results by 15 months[15]. The patients noted sensation in locations where previously they reported complete anesthesia. As a result these individuals reported feeling less handicapped and as a result the penis became more integrated into their body image. Invasive surgery is not necessary for all men with SB, but the results reiterate the importance of normal penile function to male sexuality.

\section{FERTILITY}

Infertility in SB males appears to be a common problem. Although the number of men with SB who are married and actively attempting to father a child are low, paternity rates are reported to be between 56 $73 \%[8,16]$. The likelihood of paternity is greater in those with lower lesions and in Decter's series, 7 of the 8 men who achieved paternity had L5 or sacral level lesions[8]. Infertility in men with higher lesions may be due to impotence and inability to ejaculate. In 10 males with impotence related to SB, electroejaculation revealed azoospermia in all patients[17]. These patients received a testicular biopsy and were found to have Sertoli cells only. The reasons for the subnormal infertility in this study are unclear. Normal testosterone production has been demonstrated in $90 \%$ of men with SB[8].

In men with SB who are fertile and father children, the risk of neural tube defects (NTD) in the offspring are greater than the general population. This risk is present whether the affected parent is the mother or the father. Older reports show a 3.7\% incidence of NTD in children with SB parents. This is prior to the widespread use of prenatal folic acid, however, and may be an overestimate. Without more recent data, patients should continue to be counseled of the risk of NTDs.

\section{CONCLUSIONS}

Many adult males with SB, regardless of severity of handicap, are interested in sexual activity and discussions related to sexuality should be initiated by heath care providers without assumptions. Erectile dysfunction is variable and dependent on the level of neurologic lesion, but the majority of these men respond to conventional treatments for ED, including PDE5 inhibitors. The prevalence of infertility in this population is unknown, especially in those with higher neurologic lesions. Further study is needed to determine if modern methods for treating azoospermia are effective in men with SB. Paternity is possible and men actively seeking to father children should be counseled about NTDs and preventative measures. 


\section{REFERENCES}

1. Yen, I., Khoury, M.J., Erickson, J.D. et al. (1992) The changing epidemiology of neural tube defects. United States, 1968-1989. Am J Dis Child 146, 857-861.

2. $\quad$ Glass, C. and Soni, B. (1999) Sexual problems of disabled patients. Br Med J 318, 518-521.

3. Woodhouse, C.R.J. (1998) Sexual function in boys born with extstrophy, myelomeningocele and micropenis. Urology 52, 3-11.

4. Sandler, A.D., Worley, G., Leroy, E.C., et al. (1996) Sexual function and erection capability among young men with spina bifida. Dev Med Child Neurol 38, 823-829.

5. $\quad$ Dorner, S. (1977) Sexual interest and activity in adolescents with spina bifida. I 18, 229-237.

6. Hirayama, A., Yamada, K., Tanaka, Y. et al. (1995) Evaluation of sexual function in adults with myelomeningocele. Hinyokika Kiyo 41, 985-989.

7. Game, X., Moscovici, J., Game, L., et al. (2006) Evaluation of sexual function in young men with spina bifida and myelomeningocele using the International Index of Erectile Function. Urology 67, 566-570.

8. Decter, R.M., Furness, P.D. III, Nguyen, T.A., et al. (1997) Reproductive understanding, sexual functioning and testosterone levels in men with spina bifida. J Urol 157, 1466-1468.

9. Sawyer, S.M. and Roberts, K.V. (1999) Sexual and reproductive health in young people with spina bifida. Dev Med Child Neurol 41, 671-675.

10. Diamond, D.A., Rickwood, A.M. and Thomas, D.G. (1986) Penile erections in myelomeningocele patients. Br J Urol 58, 434-435.

11. Sandler, A.D., Worley, G., Leroy, E.C., et al. (1996) Sexual function and erection capability among young men with spina bifida. Dev Med Child Neurol 38, 823-829.

12. Cass, A.S., Bloom, B.A. and Luxenberg, M. (1986) Sexual function in adults with myelomeningocele. $J$ Urol 136, 425-426.

13. Palmer, J.S., Kaplan, W.E. and Firlit, C.F. (1999) Erectile dysfunction in spina bifida is treatable. Lancet 354, 125-126.

14. Palmer, J.S., Kaplan, W.E. and Firlit, C.F. (2000) Erectile dysfunction in patients with spina bifida is a treatable condition. J Urol 164, 958-961.

15. Overgoor, M.L.E., Moshe, K., Cohen-Kettenis, P.T., et al. (2006) Neurologic bypass for sensory innervation of the penis in patients with spina bifida. $J$ Urol 176, 1086-1090.

16. Laurence, K.M. and Beresford, A. (1975) Continence, friends, marriage and children in 51 adults with spina bifida. Dev Med Child Neurol 17, 123-128.

17. Preliminary investigation of the fertility status of post pubertal males with myelodysplasia. Paper read at the International Pediatric Nephrology Association Meeting, Jerusalem, September, 1992.

This article should be cited as follows:

Bong, G.W. and Rover, E.S. (2007) Sexual health in adult men with spina bifida TheScientificWorldJOURNAL: TSW Urology 7, 1466-1469. DOI 10.1100/tsw.2007.191. 

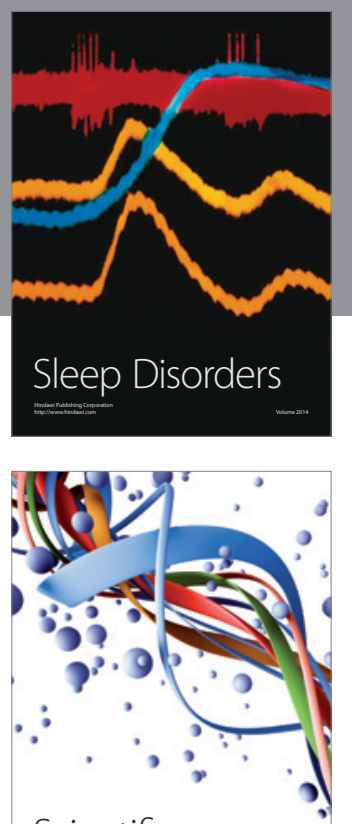

Scientifica
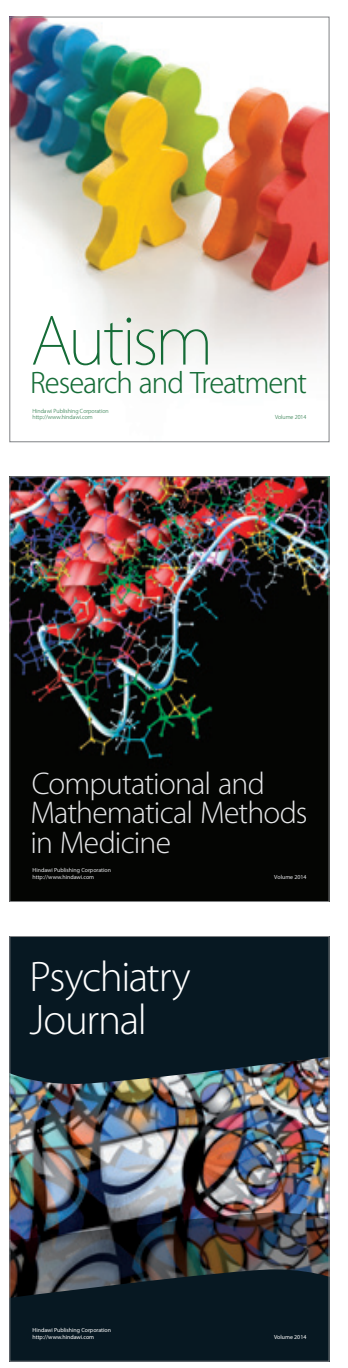
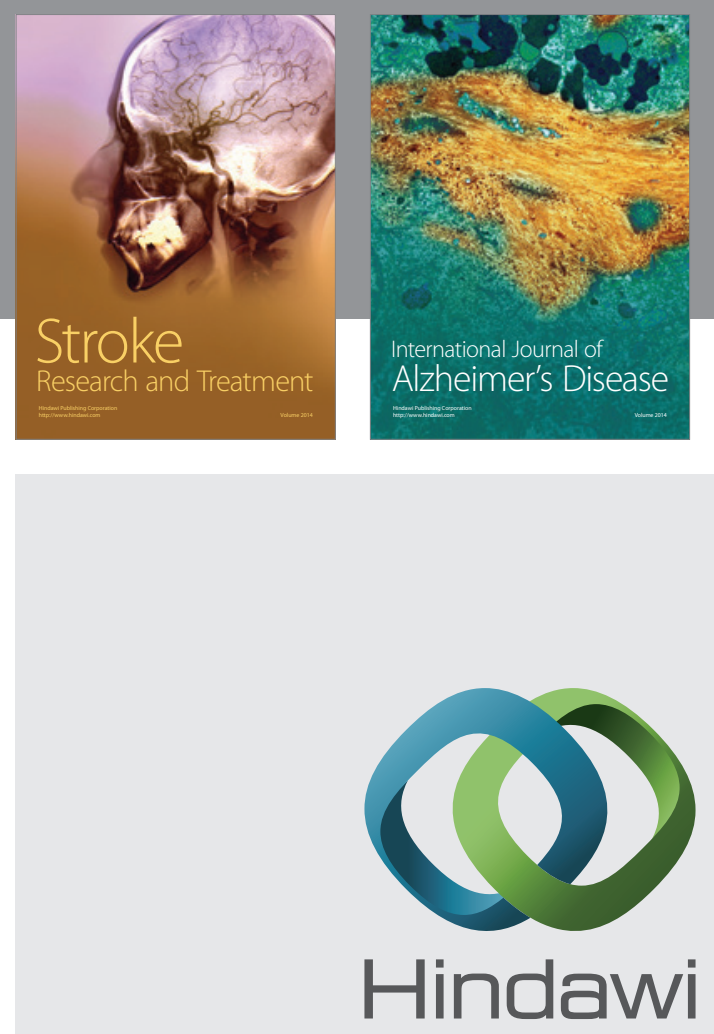

Submit your manuscripts at

http://www.hindawi.com
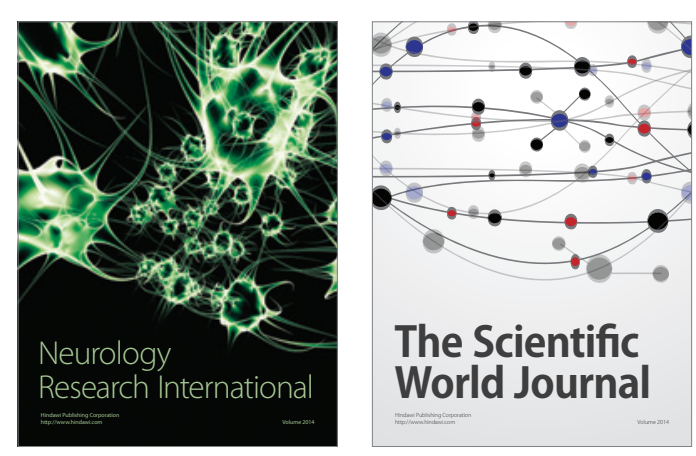

The Scientific World Journal

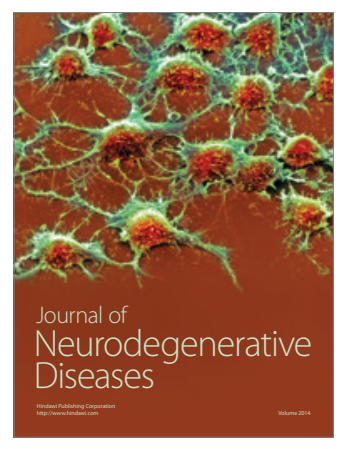

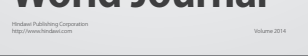

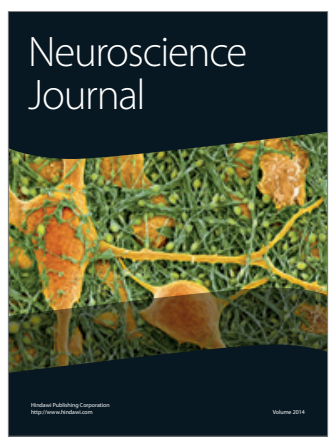

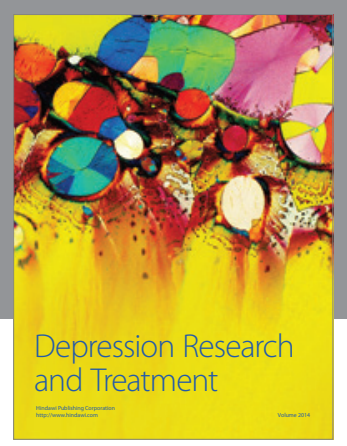
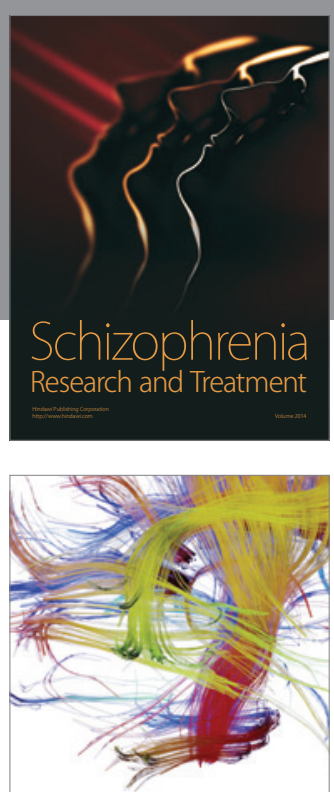

Brain Science

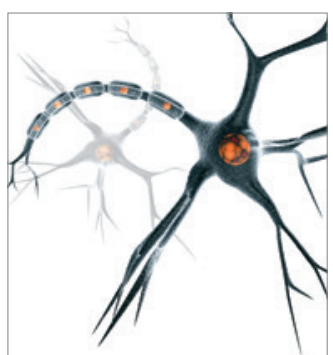

Neural Plasticity
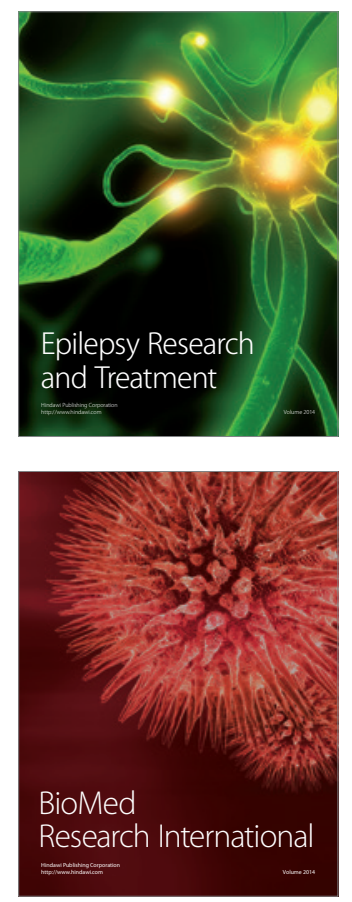

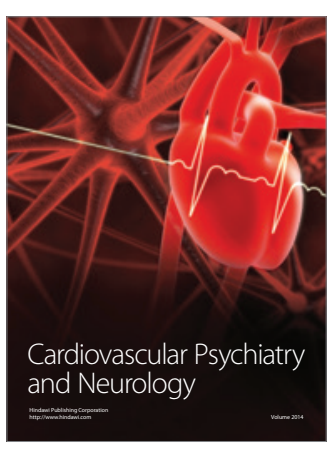

Parkinson's

Disease
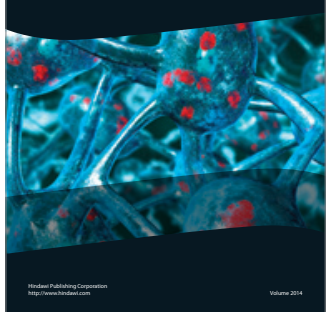